\title{
Rupturas performáticas em sites de redes sociais: um olhar sobre fissuras no processo de apresentação de si a partir de e para além de Goffman
}

\section{Beatriz Brandão Polivanov}

Doutora; Universidade Federal Fluminense, Rio de Janeiro, RJ, Brasil beatrizpolivanov@id.uff.br

\section{Fernanda Ariane Silva Carrera}

Doutora; Universidade Federal do Rio de Janeiro, Rio de Janeiro, RJ, Brasil

fernandacarrera@gmail.com

\begin{abstract}
Resumo
Uma série de estudos tem se dedicado a investigar os processos de "representação" dos sujeitos em sites de redes sociais. Boa parte deles se apoia nos preceitos da perspectiva dramatúrgica de Goffman para tal, focando-se em como os atores sociais constroem "fachadas" de si nesses ambientes de modo, em geral, a manter uma "coerência expressiva" entre seus selves on e off-line. Contudo, propomos, neste trabalho, olhar para os momentos de rupturas performáticas, isto é, quando as intencionalidades dos atores não são cumpridas, causando efeitos inesperados. Argumentamos, junto à análise exploratória de dois casos, que, por um lado, pouco tem se discutido sobre tais rupturas e, por outro, que à perspectiva goffmaniana devem ser acrescentadas bases teóricas outras e mais contemporâneas que nos permitam: a) entender as especificidades dos ambientes digitais e b) tratar os diversos actantes envolvidos, humanos e não humanos, enquanto mediadores fundamentais nessas dinâmicas.
\end{abstract}

\section{Palavras-chave}

Rupturas performáticas. Sites de redes sociais. Goffman. 


\section{Introdução}

Em 2014, a atriz Fernanda Paes Leme havia sido contratada pela empresa Sony para divulgar, através de seu perfil pessoal no Twitter, o novo aparelho de celular Xperia Z2, que permitia que fosse assistida TV digital através do mesmo. Buscando cumprir seu objetivo, Fernanda publicou o seguinte tweet no dia 27 de agosto daquele ano: "Alguém aí assistindo a novela? Tô no trânsito mas meu Xperia Z2 tem TV Digital, então dá pra acompanhar sempre !" (LEME, 2014, doc. não paginado).

Ao fazer a postagem, que adquiriu rápida visibilidade e alcance, deixando um rastro digital (BRUNO, 2012), a atriz não havia se dado conta de que o próprio aparelho celular que estava usando de fato para tal - e que não era o objeto da ação publicitária - a "delatou", informando que a mensagem fora enviada através do iPhone e não do aparelho que divulgava (ver figura 1 abaixo). Tal caso teve, como se pode imaginar, repercussão midiática em ambientes virtuais, sendo considerado uma "gafe"2 que se tornou viral ${ }^{3}$.

Figura 1 - Tweet da atriz Fernanda Paes Leme

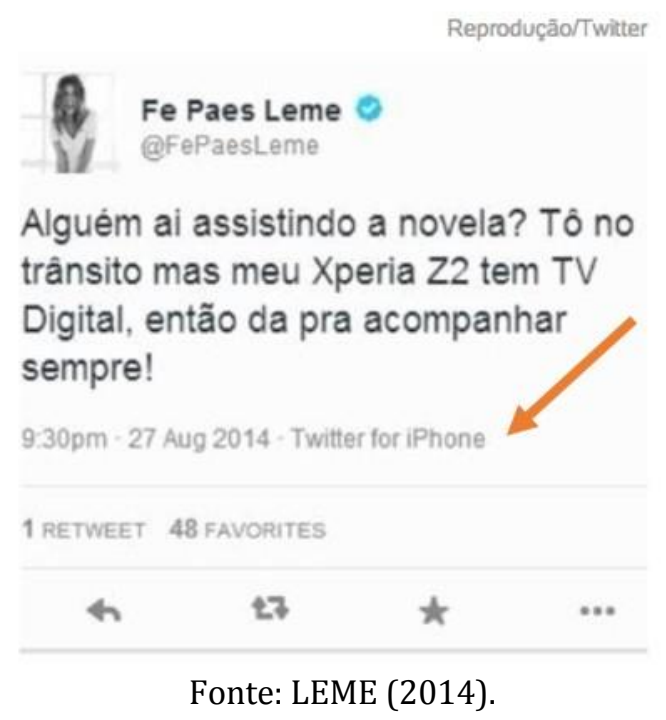

Para além de casos relacionados ao universo da publicidade e do marketing, outros

\footnotetext{
1 Optamos por manter aqui a grafia original deste texto tal como estava, mesmo que infringindo a norma culta da língua portuguesa, para manter seu caráter coloquial e supostamente espontâneo.

2 Ver, por exemplo, Uol (2014).

3 Fenômeno que diz respeito à rápida propagação de conteúdos na web, intencional ou não intencionalmente. Para uma diferenciação em relação aos chamados memes da internet ver, por exemplo, Oliveira Neta (2016).
} 
tantos têm proliferado na rede, geralmente tidos como motivo de chacota e risos, o que lhes rende um processo de viralização. Sendo considerados piadas ou conteúdos que acabam atrelados ao humor, interessa-nos neste artigo entender outro aspecto: que tipos de efeitos e significados tais casos causam enquanto rupturas na performance ${ }^{4}$ de si e quais são os agentes que atuam em tais processos. Trata-se de intencionalidades, potencialidades na construção e apresentação de si que não foram de fato atingidas, seja devido à atuação de um software que "delata" o aparelho usado na transmissão de uma mensagem, seja devido a fatores humanos, como uma amiga que interfere no vídeo sendo gravado pela outra, ao declarar seu amor para um suposto namorado que, segundo nos é informado, não existiria 5 .

Quais são, portanto, os agentes que podem interferir neste processo comunicacional? De que modos? E que consequências têm no processo de performatização dos selves em sites de redes sociais (SRSs)? Essas são as questões norteadoras que pretendemos responder aqui, procurando suprir uma lacuna nos estudos sobre construção de identidade online que pouco se atêm às dinâmicas que não operam conforme a intencionalidade dos atores sociais humanos.

Apontamos que não encontramos na revisão da literatura nacional e estrangeira investigações que se voltam para analisar momentos de ruptura ou quebra de expectativa quanto à projeção identitária que se busca construir nos SRSs. Isto é, enquanto é consensual para uma série de autores que performatizamos nossos selves para os outros nesses sites (BOYD; HEER, 2006; JESUS; SALGADO; SILVA, 2014; USKI; LAMPINEN, 2016), buscando ressaltar certos traços em geral positivos de nossas identidades e ocultar outros, em uma busca por "Coerência Expressiva” (PEREIRA DE SÁ; POLIVANOV, 2012, p. 574), pouco tem se debatido sobre tentativas que falham, expondo incoerências sobre nossos selves ou performances tidas como falsas (fake) ou inautênticas.

As dinâmicas de autoapresentação dos atores em sites de redes sociais, diferentemente de outras mídias sociais como blogs e fóruns online, pressupõem a criação de seus perfis, além da visibilidade e articulação de suas redes de contato como características desses espaços (BOYD; ELLISON, 2007; RECUERO, 2009). Além disso, tais plataformas são caracterizadas por serem ambientes não anônimos, onde os atores tendem

\footnotetext{
${ }^{4} \mathrm{O}$ conceito de performance, sabemos, é polissêmico e pode ser apropriado de modos distintos a depender dos interesses de quem o emprega. Neste trabalho, ele é tributário principalmente da obra de Goffman, ao pensar como os sujeitos performatizam a si mesmos para os outros em suas vidas cotidianas. No entanto, o termo também ecoa a partir da obra de Latour, ao entender que, conforme colocam Jesus et al., a “[...] dimensão performativa [...] é própria a toda ação, ou seja, toda ação pode ser considerada como um fazer que faz fazer." (JESUS et al., 2014, p. 252).

${ }^{5}$ Nos referimos aqui ao vídeo que ficou conhecido como "Marilene, não se mete", que foi "viralizado" (RUSSEL, 2016).
} 
a revelar o que consideram ser seus selves "reais"6 (ZHAO, GRASMUCK; MARTIN, 2008; MILLER, 2011). Dessa forma, quando certas intencionalidades não são cumpridas, afeta-se diretamente a performance de si que os atores sociais desempenham cotidianamente.

Baseamos parte de nossa discussão, assim, nas metáforas de linguagem teatral de Goffman que procuram dar conta do complexo processo de apresentação do self, entendendo-o enquanto atuação de um ator/personagem, que encena para uma plateia, buscando, em geral, manter coerência na sua encenação, mas que está sempre suscetível a rupturas através, principalmente, dos "gestos involuntários". Como ressalta o autor, tais rupturas também fazem parte da performance dos atores sociais, que só podem ser entendidos enquanto "produto de todos esses arranjos" (GOFFMAN, 2009, p. 232).

Não obstante, gostaríamos de propor um olhar sobre tal "fenômeno" que vá além somente da perspectiva dramatúrgica centrada apenas nas performances dos atores humanos. Conforme nossas observações iniciais apontaram, agentes não humanos como celulares e softwares parecem exercer papel fundamental nas dinâmicas que aqui se quer investigar. Desse modo, não devem ser desconsiderados nem tratados apenas como coadjuvantes do "cenário" que se compõe. Fazemos, assim, uma aproximação com perspectivas que podemos chamar das "materialidades da comunicação" para entender de que modos tais agentes atuam e, através de suas próprias performances, afetam diretamente as intencionalidades dos atores sociais humanos. Este trabalho não pretende, dessa forma, ser uma aplicação num sentido estrito de teorias como do ator-rede tal como proposta por Latour (2005), mas antes uma espécie de revisão das ou acréscimo às ideias de Goffman, ao argumentar que os sujeitos não performatizam a si mesmos sós, mas junto a actantes não humanos, que, mais do que meramente compor cenários, mediam e efetivamente transformam as práticas sociais.

Colocar, portanto, os objetos como ativos e tão agenciadores das ações e dos comportamentos quanto os sujeitos é percebê-los para além de uma composição de “cenário" em prol de apresentações de si, mas visando a uma aproximação com a sociologia das associações, a partir de uma descrição dos coletivos sociotécnicos que constroem a nossa percepção de um todo diverso e significante. Esses coletivos abarcam uma

\footnotetext{
${ }^{6}$ Certamente não defendemos aqui que os perfis nos SRSs podem ser considerados de forma dicotômica somente reais ou falsos, sendo muito mais complexo e nuançado o processo de performatização de si nesses ambientes, bem como a própria noção de uma autoidentidade. Apenas indicamos por ora que, conforme apontam pesquisas de variados autores, aportes teóricos e objetos empíricos, há uma tendência - principalmente em sites como Facebook - de que os sujeitos busquem criar "representações" de si entendidas enquanto "verdadeiras" ou próximas ao que consideram ser suas identidades offline. Aspectos como uso do nome "real", apresentação de informações sobre o bairro onde moram, local onde trabalham e/ou estudam, fotos de família, dentre outros, corroboram nesse sentido.
} 
heterogeneidade de modos de existência que admitem à natureza e aos objetos técnicos um papel mais complexo do que a simples instrumentalização humana. Eles também são e formam o que se entende por sociedade. "O homem não é mais a medida de todas as coisas. Não podemos mais pensar em nós mesmos como sendo especiais, muito menos tomar-nos como o pináculo da criação." (SHAVIRO, 2010, p. 1).

Podemos apontar então que o presente artigo pretende trazer duas contribuições principais:

a) a noção de "rupturas performáticas", atentando para intencionalidades na performance de si que não ocorrem como esperado, algo que carece de investigações e poderia, espera-se, enriquecer os estudos sobre construção de identidades online;

b) uma revisão em duas frentes de parte dos pressupostos goffinianos que possa tanto dar conta também dos actantes não humanos envolvidos no "teatro" da representação, quanto atualizar suas ideias para ambientes mediados de apresentação de si como os sites de redes sociais.

De modo a atingir nosso objetivo, iremos, neste trabalho, focar nossa análise exploratória em dois casos, levando em conta conjunturas distintas nas quais as intencionalidades performáticas não ocorrem como esperado nos SRSs: uma na qual o "agente principal" é um ator humano (caso da Bel Pesce) e outra na qual tal agente é um objeto (caso do Luciano Huck e o chip da Vivo).

Pretendemos construir nossos argumentos, assim, de modo teórico-empírico, visando contribuir para os estudos que estão voltados para a materialidades da comunicação na cultura digital, performance de si e construção identitária por um viés das rupturas ou das fissuras. De modo a fazê-lo iremos, em um primeiro momento, apresentar as principais contribuições da perspectiva dramatúrgica de Goffman, complementada pelos olhares de outros autores, no entendimento das performances cotidianas dos sujeitos. A seguir, adentramos mais especificamente nos ambientes online e apresentamos as especificidades das dinâmicas identitárias nesses, buscando atualizar os estudos das interações sociais e apresentação de si em contextos mediados tecnologicamente. Por fim, passamos à análise exploratória dos dois casos escolhidos, atentando para os diferentes agentes que fazem parte e atuam nas redes aqui investigadas. 


\section{Goffman e a perspectiva dramatúrgica: as performances cotidianas}

Sob o viés de sua perspectiva dramatúrgica da vida social, Goffman (2009) postula que os indivíduos, em situação de co-presença, estão automaticamente imersos em um ambiente de representação de si7. Este fato não apenas constitui as bases das interações sociais, mas é o alicerce da construção do próprio self dos indivíduos. Nesse sentido, qualquer enunciado emitido por eles é carregado de significações e aprendizados sociais que definem os seus sentidos e limites. Assim, mesmo sem proferir qualquer palavra, sua imersão corpórea, por si só, já é uma forma de agir: “'[...] apesar de um indivíduo poder parar de falar, não pode parar de se comunicar através da linguagem do corpo; é preciso dizer ou a coisa certa ou a errada." (GOFFMAN, 2010, p. 45).

Para Goffman, as interações face a face constituem-se a partir de elementos comunicacionais que fazem emergir expressões de um self que se apresenta perante o outro, isto é, as mensagens de expressão de si são “[...] o meio através do qual a informação sobre o indivíduo - seu status, humor, intenções, competência etc. - é transmitida aos outros." (SMITH, 2006, p. 35). No entanto, as escolhas discursivas apresentadas em uma interação, sobretudo, revelam impressões que o interlocutor constrói a partir do que vê; isto é, tendo como ponto de partida a representação que se apresenta à sua frente, o outro compreende o ator social não só pelo conteúdo do que se diz, mas a partir daquilo que se deixa escapar; aqueles elementos que complementam o discurso - como tom de voz, postura e movimentos faciais - que, na maioria das vezes, são involuntários (GOFFMAN, 2009, p. 199).

No contexto das interações, atores e plateia constroem sentido a partir do gerenciamento de recursos dramatúrgicos expressivos, denominados "fachada" e "cenário" O segundo consiste na significação do espaço e dos objetos para fins representacionais. Segundo Goffman (2009),

[...] é ele o alicerce sobre o qual se estabelece a coerência expressiva do ator em sua encenação, sendo produzido, geralmente, através de equipamentos fixos que constroem a paisagem na qual se tecerá o espetáculo. 0 cenário, portanto, faz parte dos aspectos cênicos da região de fachada, ou seja, aqueles que devem ser arrumados antes da representação e que, fora deles, os atores possam despir-se daquela performance. Apropriando-se das suas características, "arrumando" o seu cenário de acordo com as representações

\footnotetext{
${ }^{7}$ Conforme Polivanov (2014) aponta, talvez o termo mais adequado para tal fosse "apresentação de si", mas a obra de Goffman, The presentation of self in everyday life, foi traduzida para o português como "A representação do eu na vida cotidiana", o que leva muitos autores brasileiros a utilizarem o termo "representação", mantendo também uma proximidade com o jargão dramatúrgico.
} 
que deseja produzir, o ator pode interagir com certa coerência social (CARRERA; OLIVEIRA, 2014, p. 193).

Já a fachada é a montagem final que visa à definição da situação para a plateia, dispondo de vários elementos (como o cenário e a aparência) em prol do sucesso do que será encenado. Manter a fachada ou destruir a fachada depende da habilidade do ator em gerenciar o que deve ser mostrado e o que deve ser mantido oculto daqueles que participam da interação. Aliás, o processo de gerenciamento da fachada é diretamente dependente do nível de conhecimento da plateia a respeito do ator que representa a si na interação. Fugindo do que Goffman chama de "faux pas" - gafes cometidas pela falta de entendimento do enquadre social - ou então das "intromissões inoportunas" da plateia nos bastidores da representação - quando o outro desmascara o ator por conhecer sua região de fundo, que contrapõe a sua região de fachada -, o ator social busca esconder determinados elementos da sua vida que podem prejudicar a manutenção da sua representação (GOFFMAN, 2009).

Cabe ao ator, dessa forma, gerenciar a sua representação considerando o contexto situacional no qual se encontra e o nível de informação que a plateia detém a respeito dele, isto é, planejando a melhor maneira de encenar o espetáculo: garantindo a sua [...] circunspecção dramatúrgica. Assim, manipulando de forma coerente a sua fachada, o indivíduo constrói a sua expressividade, então, sob a existência de duas ações significantes: as expressões transmitidas e as expressões emitidas. As primeiras são aquelas de caráter proposital que, por meio de signos conhecidos por sua plateia, fazem eficiente a ação comunicativa. As segundas, por sua vez, incluem movimentos que parecem sintomáticos, não intencionais do ator, e que podem trazer a impressão de que há outros sentidos para aquela informação que fora assim transmitida (GOFFMAN, 2009).

No entanto, embora deva gerenciar sua performance em prol da legitimação de si mesmo diante do outro com quem interage, o indivíduo depende também de outros agentes sociais que fazem parte da sua "equipe" na representação. Amigos, conhecidos, familiares, por exemplo, muitas vezes podem ser o estopim para o descrédito da imagem que deseja transmitir, assim como podem ser elementos-chave para o que Goffman chama de "lealdade dramatúrgica".

Sendo assim, a dinâmica interacional obedece a uma ordem sociocultural que delimita os sentidos das ações sociais e configura-se como a estrutura que norteia os acontecimentos comportamentais dos indivíduos, instituindo ao outro o seu lugar fundamental na qualificação e significação da enunciação representada. Nesse sentido, 
existe uma relação entre os indivíduos e uma estrutura social que os submete, mas "[...] essa relação 'responde' ao sistema interativo - ou quadro - em que o papel é desempenhado." (NUNES, 1993, p. 41). Entre expectativas, representações, escolhas e delimitações situacionais, os interagentes constroem as suas relações visando a adequação comportamental aos limites impostos pela interação, isto é, a maneira com a qual o indivíduo se apresenta ao outro já estabelece os limites dos seus direitos e deveres dentro da proposta comunicativa: "Direitos e deveres fazem parte da forma como nos apresentamos aos outros e ao seu tratamento em relação a nós." (SMITH, 2006, p. 100).

Vale ressaltar que é objetivo deste trabalho é entender as interações em contextos mediados, inserindo um componente relacional caro aos ambientes digitais: a interação assíncrona e não presencial. Vastamente estudada pelos estudos dos discursos, esse tipo de interação não era o âmago do trabalho de Goffman, que tinha como intuito mapear as nuances da interação face a face e as práticas de sociabilidade em ambientes de co-presença. No entanto, o legado sociológico de Goffman já foi amplamente utilizado como embasamento analítico para a comunicação mediada pelo computador (RUTTER; SMITH, 1999; HERRING, 2000; BIRNBAUM, 2011; RIBEIRO, 2003; SCHAU; GILLY, 2003; WALTHER, 2007; BARASH et al, 2010; RIBEIRO, FALCÃO; SILVA, 2010; POLIVANOV, 2014; CARRERA, 2018; PEREIRA, 2016). Sendo assim, parece fundamental perceber as complexidades desse tipo de comunicação à luz do olhar goffmaniano sobre os processos interacionais, mas indo além dele e relacionando-o a pressupostos outros que consideram as especificidades da conversação e dinâmicas de interação social em ambientes mediados e ainda que foquem não somente nos sujeitos, mas também nos objetos, nas coisas que também são agentes nos processos comunicacionais de performatização.

\section{Especificidades dos processos de performatização de si em sites de redes sociais}

Embora os pressupostos de Goffman já tenham sido amplamente discutidos para o domínio da comunicação mediada, é relevante apontar algumas especificidades do ambiente digital que podem inserir variáveis significativas ao processo interacional online e que vão mostrar os limites de algumas proposições do autor para tais ambientes. Conforme Uski e Lampinen vão argumentar, a partir de sua investigação empírica, “[...] os escritos de Goffman sobre auto-apresentação, normas sociais e autenticidade são contestados em 
contextos de sites de redes sociais." ${ }^{\prime 8}(2016$, p. 462, tradução nossa).

Nesse sentido, destacamos aqui as quatro características essenciais dos sites de redes sociais, propostas por boyd (2008) - persistência, buscabilidade, replicabilidade e audiências invisíveis - que podem ser elementos de conexão e problematização entre os trâmites da performatização de si em ambiente face a face e aqueles que se pretende analisar neste artigo.

As quatro propriedades fundamentais que distinguem o ambiente interacional mediado (BOYD, 2008) e aqueles face a face sobre os quais Goffman se debruçava analiticamente ajudam a compreender as dinâmicas e os ajustes sociais que emergem a partir dessas novas dinâmicas comunicacionais. A "persistência" é aquela que, inclusive, alicerça as outras especificidades e instaura novas temporalidades para os discursos e a conversação. Segundo a autora, enquanto nos ambientes face a face há uma inerente efemeridade no que é dito, a comunicação mediada é gravada para posterior acesso, se necessário. Essa qualidade, assim como possibilita a existência da conversação assíncrona, também estende o período de existência de qualquer ato de fala.

A qualidade da "buscabilidade", por sua vez, é um desdobramento da persistência permitida pelas materialidades digitais. Uma vez que as identidades, os corpos e as conversações são construídas por meio de textos e imagens que ficam gravados no ciberespaço, encontrar esses rastros é uma prática facilitada. Nesse sentido, o acesso a registros antigos, por exemplo, que podem desacreditar uma representação recente ou até mesmo deslegitimar um ator em interação, é uma qualidade difícil de existir na comunicação face a face, assim como a qualidade da "replicabilidade", que dificulta o discernimento do que é original do que é cópia. Enquanto, na comunicação em co-presença, os interlocutores ouvem as suas vozes e decodificam seus objetivos imediatos, na conjuntura mediada um texto pode ser buscado e replicado para outros contextos, instaurando novos sentidos a atos de fala semelhantes. Isso se aprofunda quando as outras qualidades inserem a possibilidade de o texto ser registrado, buscado, replicado e acessado por outros públicos em outros contextos espaço-temporais.

Por fim, boyd (2008)aponta para a quarta qualidade dos sites de redes sociais: a existência das "audiências invisíveis". Enquanto na comunicação face a face é possível detectar visualmente com quem se interage, é complicado mensurar quem é o público daquilo que se diz no ambiente mediado da comunicação digital. Desse modo, Schau e Gilly

${ }^{8}$ No original: "Goffman's writing about self-presentation, social norms, and authenticity is contested in SNS contexts". 
(2003), ao analisarem páginas pessoais na web $^{9}$, vão justamente apontar os limites da perspectiva goffmaniana ao afirmar que:

Goffman (1959) ${ }^{10}$ afirma que a apresentação do self é contextual, baseada em um cenário específico e em face a um público que se pode definir e antecipar. Em contraste, websites pessoais permitem aos consumidores se auto-apresentarem 24 horas por dia, 7 dias da semana para além de um cenário regional, para o mundo virtual (SCHAU; GILLY, 2003, p. 387, tradução nossa).

Para além dessas questões relacionadas à não visibilidade da audiência, à possibilidade da comunicação assíncrona e à falta de um contexto físico específico somamse ainda as ideias de que há diferentes públicos imaginados ou intencionados em distintas plataformas, bem como contextos colapsados tanto diacrônica quanto sincronicamente.

0 primeiro ponto remete ao argumento que a própria boyd irá apresentar posteriormente (2011) e que será retomado por Ribeiro, Nejm e Miranda (2012), Polivanov (2014) e Pereira (2016), que se refere às audiências imaginadas ou intencionadas. Isto é, afirmar que simplesmente não vemos quem é nosso público em ambientes virtuais parece não dar conta de uma especificidade central dos SRSs: a lista de amigos para os quais nos direcionamos na nossa apresentação de si. Como explica a autora:

Ao servir como a audiência imaginada, a lista de amigos funciona como o público intencionado. Claro que apenas porque essa coleção de pessoas é o público intencionado não significa que seja o público real. Ainda assim, o valor de imaginar a audiência ou público é para ajustar o comportamento e auto-apresentação de alguém para se adequar às normas intencionadas daquela coletividade. (BOYD, 2011, p. 6)

Isso, inclusive, varia significativamente para cada ambiente virtual, sendo relevante refletir sobre as especificidades de blogs, fóruns e mesmo dentre os sites de redes sociais. Com isso queremos apontar que não se deve tomá-los como um todo homogêneo, mas sim buscar entender de que modos operam, podendo gerar distintas construções de quais seriam os públicos intencionados. Em termos práticos, não se espera que um sujeito tenha uma mesma audiência (ainda que imaginada) em sites como Facebook, Twitter, YouTube e Snapchat, tanto por questões dos modos como e intenções pelas quais são usados cada um deles, quanto pelos diferentes algoritmos que regem seu funcionamento, fazendo com que

${ }^{9}$ Que podemos, nesse contexto, entender como antecessores dos sites de redes sociais.

10 Os autores se referem à primeira edição do livro "A representação do Eu na Vida Cotidiana", publicada em 1959. 
as relações de "amizade" sejam recíprocas e bilaterais no Facebook, mas unilaterais, sob a lógica dos seguidores, nos demais, para dar apenas um exemplo. Poucos são os usuários que sabem como tais sites funcionam na construção das audiências, criando uma esfera semipública de visibilidade da qual, em geral, não se tem muito controle.

O segundo ponto, dos contextos colapsados diacrônica e sincronicamente e ainda temporal e espacialmente, diz respeito ao que Ribeiro, Nejm e Miranda explicam como "[...] falta de clareza quanto à delimitação de fronteiras espacial, social e temporal", que "complexifica a percepção e a consequente distinção de contextos." (2012, p. 4). Ou seja, em certos SRSs - e o Facebook ilustra bem isso - temos uma audiência composta por sujeitos que fazem parte de diferentes momentos das nossas trajetórias de vida (como infância, adolescência e fase adulta), bem como diferentes esferas sociais (escola, trabalho, igreja etc.). Isso causa, conforme argumenta Polivanov (2014), dificuldades e/ou complexidades no gerenciamento de impressão que se quer causar, uma vez que públicos outrora separados em ambientes e momentos distintos agora se encontram em um mesmo "lugar". Para Pereira (2016) isso faria com que os atores sociais preferissem "pasteurizar suas performances em rede", ao que a autora explica que:

Essa estratégia pode ser relacionada com o mínimo denominador comum proposto por Hogan (2010) para adequar os conteúdos publicados a um parâmetro agradável para a média de amigos reunidos em uma rede social. Essa prática seria mais inclusiva, diminuiria o risco de alienação ou indisposição com amigos, mas também diminui o impacto da performance no que diz respeito à autenticidade de cada ator, uma vez que é difícil otimizar uma performance para agradar a todos os indivíduos de uma coletividade eclética (PEREIRA, 2016, p. 112).

Claro que devemos ter em conta que diferentes sujeitos disputam distintos valores em rede. Há, assim, aqueles que se interessam efetivamente por criar uma performance que possa ser tida como autêntica e crível, em consonância com o que entende que sejam traços identitários seus fora dos ambientes online. Contudo, há também os que buscam valores outros como comicidade ou popularidade, independentemente de construções mais adequadas ou coerentes socialmente. Por isso, enfatizamos a importância de analisar casos específicos dentro de seus contextos, buscando fugir de generalizações que não deem conta dos processos de performatização de si nos SRSs. Ainda mais sendo objetivo deste trabalho focar nas rupturas performáticas, deve-se atentar para os valores e intencionalidades em jogo em diferentes casos. 


\section{Rupturas nas intencionalidades performáticas: análise dos casos}

Com a definição do aparato teórico, buscaremos, portanto, nos debruçar sobre algumas das novas nuances e dinâmicas de apresentação de si que os SRSs trazem, sobretudo aquelas que podem gerar incongruências performáticas e constrangimentos interacionais, a partir da mediação de agentes diversos. São descritos os procedimentos metodológicos da análise a seguir.

\subsection{Procedimentos metodológicos}

Conforme apontamos no início deste trabalho nos interessa aqui investigar, a partir de uma seleção intencional de dois casos, de que modos determinadas performances de si sofrem rupturas que causam efeitos inesperados para os sujeitos envolvidos em SRSs. Cabe destacar que a seleção dos dois casos aqui analisados se deu a partir dos seguintes procedimentos de pesquisa: (1) em um momento inicial foram levantados mais de 30 casos nos quais um determinado sujeito ou marca passou por uma situação que poderia ser configurada como uma ruptura de intencionalidade performática. A seguir, (2) procedeu-se à categorização inicial de tais casos, a partir dos seguintes eixos: (a) com quem aconteceram as rupturas (sujeitos "comuns", marcas, celebridades, dentre outros), (b) quais os principais agentes de invalidação da performance (se, por exemplo, teria sido outro sujeito ou um software) e (c) quais as consequências sociais dessas rupturas para os sujeitos/instituições com quem ela acontece (perda de contrato no caso de celebridades, reconstrução da carreira, bullying etc.) ${ }^{11}$. Argumentamos, em relação ao ponto "b", que haveria ao menos esses dois tipos de casos de rupturas: aqueles ocasionados principalmente por agentes humanos e aqueles nos quais o agente fundamental causador não é humano, mas pode ser desde um software até um espelho12. Por fim, (3) tendo em vista o escopo deste trabalho, selecionamos um caso de cada um desses dois tipos, dentre aqueles que tiveram ampla

\footnotetext{
11 Tais procedimentos foram feitos como parte do projeto de pesquisa de iniciação científica (PIBIC/UFF/CNPq) "Rupturas em performances identitárias online: levantamento e análise de casos em sites de redes sociais”, coordenado por Beatriz Polivanov e desenvolvido junto aos alunos do Curso de Estudos de Mídia Juliano Coelho e Isabel Moraes.

12 Aqui nos referimos aos inúmeros casos de fotos (mais especificamente selfies) que são postadas, em geral por jovens, em sites como Facebook visando à construção de uma imagem sexualmente desejável e atraente, mas que tem tal intencionalidade rompida à medida que figuram, no plano de fundo de tais imagens, sujeitos, animais ou objetos que, por exemplo, desconstroem uma idealização do que seria sexy em nossa cultura (como a imagem da mãe sentada ao vaso sanitário ou um cachorro fazendo suas "necessidades"), tornando a performance passível de riso e até escárnio.
} 
repercussão na web ${ }^{13}$, de modo a entendermos como operam os agenciamentos e quais são os efeitos sociais que causam.

Trata-se aqui de uma análise de cunho exploratório, tipo de pesquisa que, de acordo com Gil, "[...] é realizado especialmente quando o tema escolhido é pouco explorado", sendo "passível de investigação [futura] mediante procedimentos mais sistematizados." (GIL, 1989, p. 44-45). Nesse sentido, por não haver ainda literatura ou análises empíricas consolidadas que se debrucem sobre o que está sendo chamado neste trabalho de rupturas de intencionalidades performáticas, iremos nos voltar primordialmente à descrição e análise, com base nos pressupostos teóricos trazidos, dos dois casos.

Seguimos, assim, nossa intenção de avançar em relação a determinados pressupostos da perspectiva dramatúrgica de Goffman (ainda que possam ser úteis até certo ponto) e mesmo suas apropriações em contextos mediados tecnologicamente.

\subsection{Caso 1: Bel Pesce}

O primeiro caso que abordamos aqui é o de Bel Pesce, apelidada por alguns de "menina do vale", por ter morado no Vale do Silício. Trata-se de uma jovem mulher brasileira que constrói sua imagem enquanto uma empreendedora inovadora cuja parte da receita financeira vem das palestras que ministra sobre sua história de sucesso. Ela faz parte de um grupo de sujeitos "[...]que passam de empreendedores anônimos a figuras públicas, com a ajuda principalmente da internet e seus suportes digitais midiáticos, por meio de seus discursos e narrativas de vida inspiracionais apresentadas [...] no Facebook." (FIGUEIREDO, 2016, p. 2). Para conquistar a construção de tal imagem, foram centrais alguns elementos que trariam reputação à sua figura: ela possuiria uma série de diplomas (ao menos um do renomado MIT, Massachusetts Institute of Technology) e teria fundado algumas empresas de sucesso. 0 uso dos verbos no futuro do pretérito na frase anterior não é casuístico: Bel acabou gerando uma relevante controvérsia, usando aqui o termo de Latour (2005), ao ter sua própria narrativa de vida questionada.

0 pedido da palestrante por financiamento coletivo para uma hamburgueria ${ }^{14}$ foi o ponto de partida para que o blogueiro Izzy Nobre buscasse adentrar nos bastidores da

\footnotetext{
13 Os dois casos aqui selecionados tiveram ampla visibilidade e espalhabilidade na rede, deixando uma série de rastros digitais (BRUNO, 2012) que permitiram a análise, conforme se verá na seção abaixo.

14 Sobre o caso, ver, por exemplo Fonseca (2016).
} 
representação de si de Bel Pesce como empreendedora de sucesso e graduada por universidades de renome internacional. Com o recém vencedor do programa de televisão Masterchef Brasil Leonardo Young e José Luiz Soares, que escreve para o site de gastronomia e viagens "Do Pão ao Caviar"15, Bel Pesce lança uma campanha de crowdfunding para o lançamento do negócio, que prevê recompensas aos financiadores de acordo com o valor concedido. Uma vez reunida, portanto, com mais dois outros sujeitos "bem-sucedidos" para solicitar dinheiro alheio para um empreendimento, Bel Pesce emitiu uma impressão que seria incongruente com sua fachada de sucesso. Afinal, por que alguém com tanto reconhecimento, sucesso, experiência e, presume-se, também capital financeiro deveria pedir dinheiro para tal projeto16? Esse pedido, portanto, é o estopim para a percepção do engodo, estimulando questionamentos acerca de sua "representação de si" e "revolta" por parte de atores sociais na internet. Nem mesmo o cancelamento posterior da ação em virtude da repercussão negativa foi suficiente para interromper os efeitos prejudiciais à sua imagem.

Assim, em artigo publicado no site medium.com ${ }^{17}$, Izzy destrincha os ditos e os nãoditos de Bel Pesce, fazendo uso dos artifícios e das qualidades do ambiente digital para buscar desencaixes entre o que ela performatiza, o que diz a sua vida passada e o que pode ser comprovado pelos documentos que apresenta para legitimar os seus discursos. Nesse sentido, o blogueiro realiza uma "intromissão inoportuna" nos bastidores da representação de si da palestrante, revelando acontecimentos e provocando questionamentos que enfraqueceram as pretensões relativas à sua performance de sucesso.

Essa intromissão, é importante destacar, foi possibilitada pela permanência das informações no ciberespaço, dos rastros digitais (BRUNO, 2012), inclusive a respeito do currículo de Bel Pesce, sua trajetória, seus trabalhos, textos, entrevistas e perfis em sites de redes sociais, assim como também pela "buscabilidade" (BOYD, 2008) inerente ao ambiente, que facilitou o processo de checagem e avaliação. Dessa forma, os inúmeros documentos postos em análise colocaram em evidência intenções discursivas que eram destaque em alguns enunciados ou materiais e em outros eram ausentes (sobretudo em relação aos seus diplomas), o que provocou a emergência de gestos involuntários significativos para a deslegitimação da performance de Bel Pesce. Sobre isso, destaca-se o questionamento de

\footnotetext{
15 Disponível em Do Pão ao Caviar (2017).

${ }^{16}$ Assim como seu parceiro Leonardo, que havia acabado de ganhar um prêmio em dinheiro por ter sido vencedor do programa Masterchef.

17 Ver artigo em Nobre (2016).
} 
Izzy Nobre:

Bel se formou. Tem dois diplomas. Mas a linguagem que ela usou não deixa isso claro, visto que alguém poderia dizer exatamente a mesma coisa que ela falou, SEM TER SE FORMADO. Farei mais uma vez a comparação: é como dizer 'cursei direito'. Você tem diploma de direito? Talvez sim. Talvez não. A frase 'cursei direito', sozinha, não é conclusiva. É vaga. Pode ser usada para enganar, e frequentemente é. (NOBRE, 2016, não paginado).

A desconfiança do blogueiro reside na incongruência entre a intencionalidade do gerenciamento de impressões (GOFFMAN, 2009) de Bel Pesce, que parece buscar "transmitir" uma imagem de sucesso profissional pela sua múltipla formação, mas que "emite" uma aparência de engodo ao utilizar linguagem vaga, incerta, passível de dubiedade. Izzy alerta para os sentidos que ecoam dos não-ditos, colocando holofotes em pontos precisos da enunciação e dos contextos que são fundamentais para a validação ou descrédito da fachada de um ator que se coloca à interação. Em outro momento, resume:

\begin{abstract}
Além disso, dentro da cultura norte-americana, a linguagem do 'tenho um major em X' é típica de alguém que cursou algo, não completou, mas quer ainda usar este fato para imbuir-se de autoridade acadêmica num determinado assunto, levando o interlocutor a concluir que está falando com um especialista formado naquela área. (NOBRE, 2016, online).
\end{abstract}

Bel Pesce, portanto, não conseguiu se isentar das especificidades do ambiente digital que não existiriam se o contexto das suas palestras e das suas representações de si fossem restritas ao ambiente face a face analisado por Goffman. Enquanto a temporalidade de uma palestra limita o acesso a informações sobre a fachada do ator - restringindo a plateia à avaliação do domínio do rosto e da voz -, no ciberespaço é possível se demorar sobre os conteúdos, analisando minuciosamente as inconsistências, os deslizes e os descuidos da performance apresentada. Sendo assim, a palestrante deparou-se com as ameaças das "audiências invisíveis", que ao sinal de mínima contradição performática, faz uso irrestrito da impiedosa "replicabilidade" (BOYD, 2008).

Ademais, Pesce enfrentou a problemática de uma equipe pouco preparada para o espetáculo. Distraída, a equipe descuidou-se da lealdade dramatúrgica, colocando em voga mais elementos para uma possível deslegitimação da sua fachada. De acordo com Izzy Nobre, Wences Casares (fundador de uma das empresas que Bel Pesce diz ter co-fundado) afirmou que a palestrante apenas foi sua funcionária, participando do projeto um ano depois da sua fundação. No entanto, a resposta, que foi dada através do Twitter, foi apagada logo 
Rupturas performáticas em sites de redes sociais: um olhar sobre fissuras no processo de apresentação de si a partir de e para além de Goffman

depois. A insegurança na informação, segundo Izzy, deixa dúvidas sobre a real participação de Bel Pesce na empresa.

Em um projeto da Microsoft, ainda enquanto Bel Pesce afirmava ser desenvolvedora da interface, a inconsistência recaiu novamente sobre a sua representação. Nesse caso, a página no LinkedIn do projeto não citava a palestrante em nenhum momento do processo de desenvolvimento até a publicação do texto do blogueiro Izzy Nobre. Logo após a publicização da crítica, o nome de Bel Pesce aparece adicionado como participante do projeto, mas o "faux pas" (GOFFMAN, 2009) já havia se efetivado pelo esquecimento da equipe. A rápida correção não pôde evitar os rastros deixados pela materialidade, que indicou exatamente quando a mudança foi realizada, conforme ilustra a figura 2 abaixo.

Figura 2 - Trecho do artigo "Bel Pesce e o empreendedorismo de palco: porque a Menina do Vale não vale tanto assim"

É estranho que uma página intocada desde 2008 seja atualizada horas pra citar a Bel poucas horas após a publicação desse texto. Não parece ter enganado ninguém, no entanto, se julgarmos pelos comentários da página:

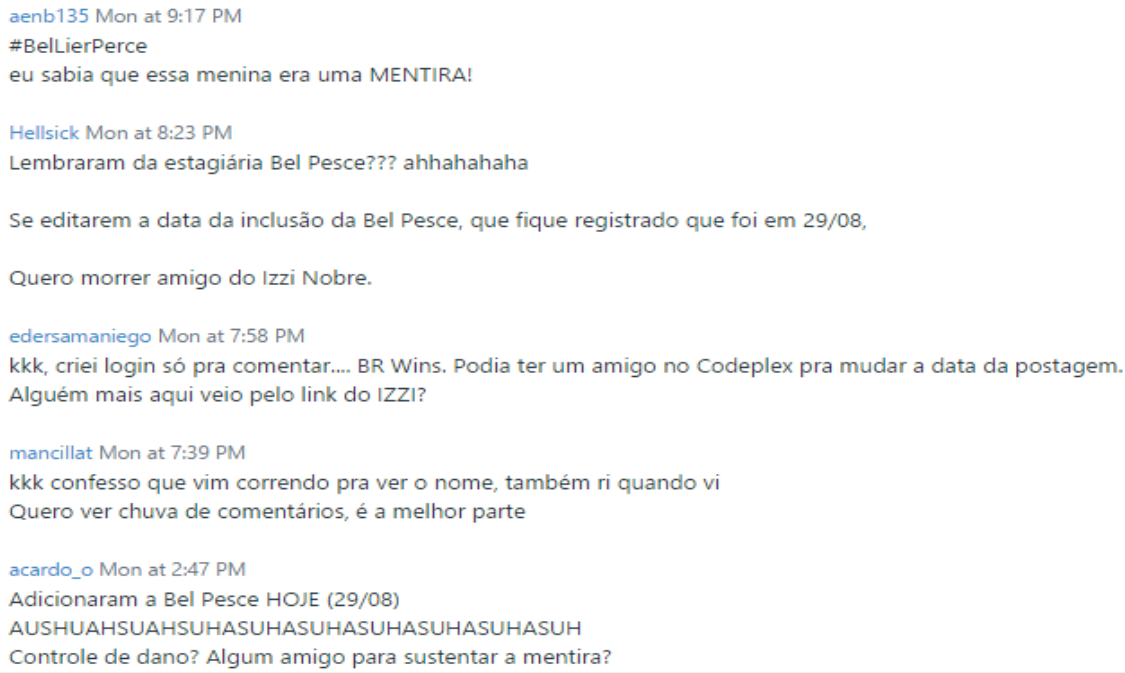

Fonte: Adaptada de Nobre (2016).

O caso continua gerando uma série de posicionamentos e repercussões diversos 
entre os defensores e delatores de Bel ${ }^{18}$, estando tal controvérsia ainda possivelmente longe de se estabilizar enquanto uma "caixa-preta" (LATOUR, 2005). A partir dele queremos deixar claro que a divisão inicial nas duas categorias que propõem que as rupturas performáticas podem se dar pela agência primordial de humanos e não humanos é certamente um tipo ideal (em termos weberianos), no sentido de que não é possível dar ao sujeito (no caso o blogueiro Izzy, detonador das polêmicas) toda a agência na controvérsia.

Assim, certamente a "contra-performance" de Izzy só foi de fato possível a partir da mediação fundamental de seu blog (para citar apenas outro agente relevante) e as afetações que gerou através dos sites de redes sociais da palestrante. Isto é, qualquer olhar sobre tais rupturas performáticas em sites de redes sociais deve entender seus agentes e efeitos enquanto redes necessariamente sociotécnicas, enquanto ações distribuídas entre diversos actantes que não devem ser vistos isoladamente (LATOUR, 2005). Não obstante, defendemos que na conformação da rede para a qual olhamos aqui, o agente humano, o blogueiro, foi o causador principal da ruptura. Sua atuação foi fundamental para que ocorresse, ainda que sim, mediada por outros agentes. Passamos agora para um caso que consideramos distinto, justamente por ter tido como "detonador" da ação um actante não humano.

\subsection{Caso 2: Luciano Huck e o chip da Vivo}

As imagens, no contexto dos SRSs, são elementos essenciais para a congruência entre o que se quer dizer e o que de fato se diz, uma vez que muitas vezes podem deixar escapar sentidos e permitir a emissão de informações a serviço do descrédito e da invalidação. 0 caso da atriz Fernanda Paes Leme, mencionado no início do artigo, ilustra a necessidade de composição minuciosa da performance social em prol da sua validação pela plateia. Esta, potencialmente atenta a todos os elementos que produzem o cenário da representação de uma pessoa pública (sobretudo por se tratar de uma publicação com fins publicitários), é o balizador do sucesso ou do fracasso da performance.

Caso semelhante aconteceu com a TIM e seu garoto-propaganda Luciano Huck: o

\footnotetext{
${ }^{18}$ Ver, por exemplo, o vídeo publicado por Izzy (2017) em seu canal no YouTube, no qual o blogueiro afirma inclusive que já teria sido criado o verbo "belpescear" que se referiria ao ato de mentir sobre o próprio currículo / formação. Outros materiais de fontes distintas também corroboram a ideia de que o caso tem repercussões até recentemente: ver, por exemplo, o vídeo publicado por Billy Anderson (2017), que analisa a linguagem corporal de Bel, tida como "farsa". Em trabalhos futuros, pretende-se discutir ainda como agentes envolvidos na controvérsia podem também buscar construir capital social a partir da mesma.
} 
apresentador, que na época protagonizava peças publicitárias da empresa de telefonia havia cerca de dois anos, quis comemorar a conquista de 10 milhões de seguidores no Facebook. Para isso, tirou uma foto da tela do seu aparelho celular, na qual se podia ver o número de seguidores atingidos, e publicou a imagem no site de rede social Instagram. Nada disso teria sido problemático, a não ser pelo fato de que a postagem da tela de seu celular deixou escapar a utilização de um chip da concorrente de sua patrocinadora, a VIVO (ver figura 3 abaixo).

Figura 3 - Post de Luciano Huck

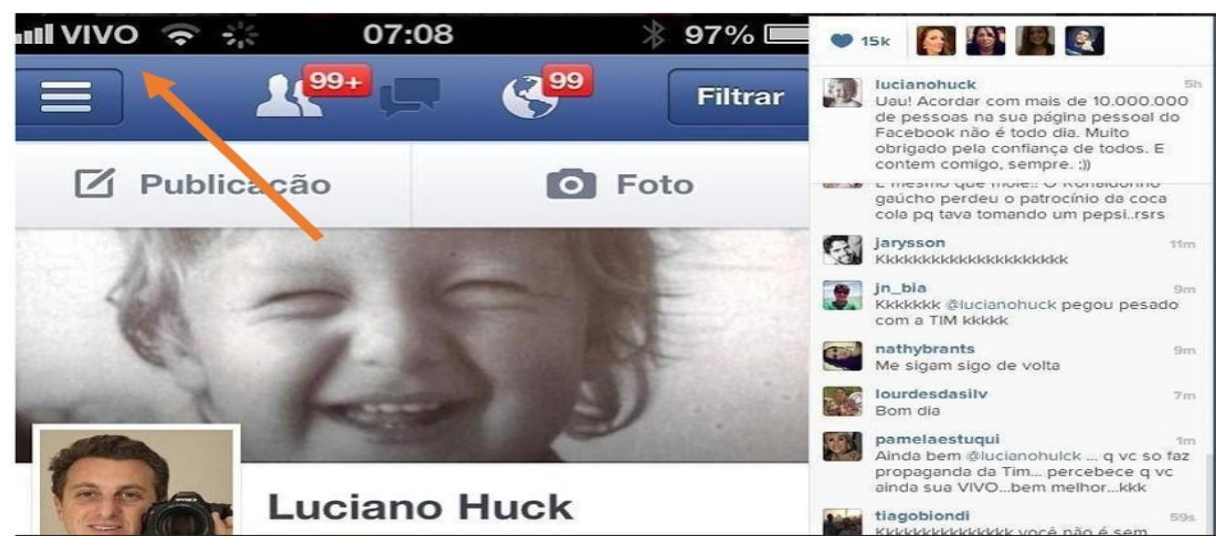

Fonte: Lopes, $2013^{19}$.

Esse movimento sintomático, não intencional, deslocou os sentidos desejados pela fachada, emitindo significados que se mostraram mais proeminentes que aqueles intencionados pela expressão transmitida de alegria pela quantidade de seguidores. Rapidamente seguidores do apresentador postaram comentários embaixo da imagem publicada no Instagram afirmando, por exemplo, "Ainda bem, @lucianohuck, que você só faz propaganda da Tim... percebe-se que você ainda usa Vivo... bem melhor... kkk"20 ou "kkkkkkkkkkkk você não é sem fronteiras?!!!!!" remetendo ao slogan da TIM.

Atentar para a produção do cenário na construção da fachada de cada proposta interacional é, portanto, fundamental para o direcionamento interpretativo desejado, evitando emitir sentidos malquistos ou até mesmo contrários à intencionalidade inicial. Neste caso, se a intencionalidade da postagem era a comemoração do número de seguidores no Facebook, que deveria ser seguida por curtidas e comentários de aprovação, o que

\footnotetext{
${ }^{19}$ Imagem e relato do caso disponíveis em Lopes (2013).

${ }^{20}$ Optamos por transcrever o texto utilizando aqui a norma culta da língua portuguesa para que seu sentido pudesse ficar mais claro.
} 
ocorreu - também e com grande potência de espalhamento da mensagem ${ }^{21}$ - foi um efeito humorístico que desacredita ou rompe (ainda que parcialmente) a performance pretendida, a partir de um agente não humano: o chip.

Indo além, mais do que meramente um elemento do cenário que poderia passar despercebido, o minúsculo chip da marca Vivo agenciou um sentido outro para a performance de Huck, alterando sua intencionalidade inicial. Nesse sentido, evocamos o argumento de Bruno Latour, a partir da Teoria Ator-Rede (2005), ao reivindicar a não definição, antes do rastreamento da rede, de quem é ou não um ator, um agente ativo, um actante. Isto é, não se pode afirmar essa condição apenas pela sua composição material, se humano ou não humano. Estes dois elementos são colocados em um mesmo plano significante, devendo ser avaliado, naquela associação, qual deles age sobre o outro e de que modos, em um movimento de fluxo constante. Sendo assim, ao analista cabe preocupar-se com os efeitos que a rede, os coletivos sociotécnicos, trazem para o curso de cada ação. Na análise aqui proposta, essa perspectiva pode ser relevante para a compreensão das dinâmicas complexas do ambiente digital, reservando um lugar significativo às influências da materialidade para o curso das ações e dos comportamentos que ali são empreendidos, como no caso do chip.

Ainda, se entendermos os perfis dos sujeitos em sites de redes sociais como redes, tal como propõe Malini (2016), conseguimos complexificar as apropriações que são feitas do pensamento de Goffman ao investigar performances de si em SRSs, argumentando que tais perfis são muito mais do que uma mera representação dos atores sociais em uma plataforma, que estariam ali "duplicados", estando seus verdadeiros "donos" e soberanos agentes por detrás das telas maquinando cada ação a ser feita. Casos como este de Luciano Huck vão nos mostrar que há imbricamentos humano-maquínicos - no caso o apresentador, mais seu celular, mais o chip da Vivo, mais o Facebook, para apontar alguns deles que nos interessam aqui - em geral, quase imperceptíveis no cotidiano, que emergem e nos fazem dar conta de sua existência que em outros momentos poderia ser imperceptível.

Vale salientar que não é interesse deste trabalho discorrer mais especificamente sobre a questão da imagem das celebridades ou das associações entre marcas e pessoas famosas como estratégia publicitária. Não obstante, estamos cientes das diferenças que as "rupturas performáticas" para sujeitos tidos como "comuns" e aqueles com mais

\footnotetext{
210 caso é facilmente encontrado até hoje com uma simples busca no Google, tendo sido noticiado em vários blogs e portais de notícias como uma gafe comercial.
} 
visibilidade, como celebridades, engendram. Assim, podemos afirmar que Luciano Huck e Fernanda Paes Leme têm maior visibilidade nas suas ações e comportamentos sociais, o que vai afetar diretamente os modos como suas intencionalidades performáticas são rompidas 22 . Reforçamos, contudo, que aqui estamos preocupados em como sujeitos, imersos nos contextos de sociabilidade digital, lidam com o gerenciamento de suas impressões em meio às influências de agentes humanos e não humanos.

\section{Considerações finais}

No contexto dos SRSs, percebe-se que a performatização de si envolve complexidades, sobretudo a respeito do papel dos aparatos e da mediação, que problematizam a centralidade dos sujeitos no curso das interações sociais. Considerando que, a partir das perspectivas das materialidades da comunicação, o status de ator é concedido ao agente que modifica, produz uma diferença na prática processual, vimos que esse desvio pode ser produto de um comportamento material. No entanto, evitamos aqui uma perspectiva de determinismo tecnológico, assim como não buscamos conhecer a origem das ações, mas o pressuposto principal residiu no fato de que toda ação e interação é sempre diluída na rede. Pensando desse modo, todos os percursos da vida social e, inclusive, das performatizações de si, estão condicionados aos diversos elementos cujo contato se destaca e constrói uma diferença; mais do que isso, toda a subjetividade é produzida a partir de suas relações dentro de um coletivo sociotécnico e não apenas humano.

A partir da exploração inicial que fizemos aqui ao que estamos chamando de "rupturas performáticas", podemos chegar a alguns pontos de partida preliminares que carecem, claro, de aprofundamentos e encaminhamentos:

a) há uma variedade muito mais ampla de tipos de casos de rupturas que vão engendrar sentidos e práticas sociais particulares, porém dentre eles podemos apontar que alguns têm como "detonador" principal agentes humanos (ainda que seus discursos sejam mediados) e outros agentes não humanos e aqui focamos apenas nos casos de rupturas não intencionais, mas acreditamos que haja também aqueles intencionalmente feitos, que carecem também de

\footnotetext{
${ }^{22}$ Em trabalhos futuros pretendemos discutir como certas rupturas estão relacionadas ao atrelamento entre celebridades e produtos que supostamente consumiriam e deveriam publicizar, como os casos de Luciano Huck e Fernanda Paes Leme evidenciam, que geram um tipo de "quebra de expectativa" específica, que costuma afetar diretamente os consumidores e anunciantes.
} 
investigação;

b) o que parece estar em jogo nos dois casos analisados é um rompimento com certa noção de autenticidade, conceito que será fundamental em trabalhos futuros;

c) deve-se também olhar de forma minuciosa para as particularidades dos casos como os aqui apresentados - que envolvem celebridades (em maior ou menor grau) e aqueles que se dão com sujeitos tidos como "comuns", fora de uma esfera midiática de grande visibilidade;

d) é relevante atentar para a repercussão, a "espalhabilidade" que certos casos conquistam, causando processos de viralização e mimetização;

e) não se deve perder de vista um olhar sensível para com os sujeitos envolvidos em tais rupturas e seus efeitos sociais, econômicos e políticos - para além de gafes pontuais que adquirem tom humorístico alguns casos podem causar constrangimentos graves. Por fim, ressaltamos a importância de investigar o "fenômeno" a partir de chaves de leituras que nos permitam maior complexidade e adensamento, ainda que tal tarefa não seja facilmente empreendida.

\section{Referências}

ANDERSON, Billy. Bel Pesce e suas mentiras, linguagem corporal. In: YOUTUBE. San Mateo, 2017. Disponível em: <https://www.youtube.com/watch?v=FT7te1f7Trw>. Acesso em: 13 ago. 2017.

BARASH, Vladimir et al. Faceplant. Impressions (Mis)management in Facebook Status Updates. In: INTERNATIONAL AAAI CONFERENCE ON WEBLOGS AND SOCIAL MEDIA, 4., Washington. Proceedings... Washington: Association for the advancement of artificial intelligence, 2010. p. 207-210.

BIRNBAUM, Matthew. Taking Goffman on a tour of Facebook: college students and the presentation of self in a mediated digital environment. ProQuest: Ann Arbor, 2011.

BOYD, danah. Social Network Sites as networked publics: Affordances, Dynamics, and implications. In: PAPACHARISSI, Zizi (Ed.). A networked self: Identity, Community and Culture on Social Network Sites. London: Routledge, 2011, pp. 39-58.

BOYD, danah. Why Youth Love Social Network Sites: The Role of Networked Publics in Teenage Social Life. In: BUCKINGHAM, David (Ed.). Youth, identity, and digital media. Cambridge: The MIT Press, 2008. p. 119-142. 
BOYD, danah; ELLISON, Nicole. Social network sites: definition, history, and scholarship. Indiana: Journal of Computer-Mediated Communication, Indiana, v. 13, n. 1, Out. 2007.

BOYD, danah; HEER, Jeffrey. Profiles as Conversation: networked identity performance on friendster. Hawai'i International Conference on System Sciences, 39., 2007, Kauai.

Proceedings... Kauai: IEEE Computer Society, 2006.

BRUNO, Fernanda. Rastros digitais: o que eles se tornam quando vistos sob a perspectiva da teoria ator-rede? In: ENCONTRO ANUAL DA COMPÓS, 21., 2012, Juiz de Fora. Anais... Juiz de Fora: Associação Nacional dos Programas de Pós-graduação em Comunicação, 2012.

CARRERA, Fernanda. Marcas humanizadas e suas interações sociais com consumidores no ambiente digital. Curitiba: Appris, 2018.

CARRERA, Fernanda; OLIVEIRA, Thaiane. Performance e teatralidade na publicidade pervasiva: análise dos cases Skyfall e Fantastic Delites. Intexto, Porto Alegre, n. 30, p. 184201, 2014.

DO PÃO AO CAVIAR. Quem somos. 2017. Disponível em:

<http://dopaoaocaviar.com.br/quem-somos/>. Acesso em: 30 abr. 2017.

FIGUEIREDO, Camila. A cibercultura e as narrativas de vida inspiracionais da cultura empreendedora: de pessoas "comuns" a celebridades. In: CONGRESSO BRASILEIRO DE CIÊNCIAS DA COMUNICAÇÃO, 39., INTERCOM, 2016, São Paulo. Anais... São Paulo: INTERCOM, 2016.

FONSECA, Mariana. Crowdfunding da hamburgueria de Leo e Bel Pesce é cancelado. Exame, São Paulo, 5 set. 2016.

GIL, Antonio. Métodos e técnicas de pesquisa social. 2. ed. São Paulo: Atlas, 1989.

GOFFMAN, Erving. A representação do eu na vida cotidiana. Petrópolis: Vozes, 2009.

GOFFMAN, Erving. Comportamento em lugares públicos: notas sobre a organização social dos ajuntamentos. Petrópolis, RJ: Vozes, 2010.

HERRING, Susan. Gender differences in CMC: findings and implications. CPSR Newsletter, Seattle, v. 18, n. 1, 2000.

JESUS, Eduardo; SALGADO, Tiago; SILVA, Polyana. Performances e produção de efeitos subjetivos no Instagram e no YouTube. Revista Fronteiras: estudos midiáticos, São Leopoldo, v. 16, n. 3, p. 243-256, 2014.

LATOUR, Bruno. Reassembling the social: an introduction to actor-network-theory. New York: Oxford University Press, 2005.

LEME, Fernanda Paes. [Tweet da atriz Fernanda Paes Leme]. 2014. 
LOPES, Yuri. Contratado da Tim, Luciano Huck posta foto usando celular da Vivo. A Redação, Goiânia, 2013.

MALINI, Fabio. Um método perspectivista de análise de redes sociais: cartografando topologias e temporalidades em rede. In: ENCONTRO ANUAL DA COMPÓS, 25., 2016, Goiânia. Anais... Goiânia: Associação Nacional dos Programas de Pós-graduação em Comunicação, 2016.

MILLER, Daniel. Tales from Facebook. Cambridge: Polity, 2011.

NOBRE, Izzy. Bel Pesce e o empreendedorismo de palco: porque a Menina do Vale não vale tanto assim. In: MEDIUM. 2016.

NOBRE, Izzy. E a Bel Pesce continua mentindo. 2017. Disponível em:

<https://www.youtube.com/watch?v=SU7nOgWxHV4>. Acesso em: 12 maio 2018.

NUNES, João. Erving Goffman: a análise de quadros e a sociologia da vida quotidiana. Revista Crítica de Ciências Sociais, Coimbra, Portugal, n. 37, p. 33-49, jun. 1993.

OLIVEIRA NETA, Juracy. A imagem técnico-memética no Facebook. 2016. Dissertação (Mestrado em Comunicação) - Programa de Pós-Graduação em Comunicação, Universidade do Estado do Rio de Janeiro, Rio de Janeiro, 2016.

PEREIRA DE SÁ, Simone; POLIVANOV, Beatriz. Auto-reflexividade, coerência expressiva e performance como categorias para análise dos sites de redes sociais. Revista Contemporânea, Salvador, v. 10, n. 3, p. 574-596, 2012.

PEREIRA, Marília. Éthos em rede: dinâmicas, apropriações e implicações éticas do éthos conectado no Facebook. 2016. Dissertação (Mestrado em Comunicação e Práticas de Consumo) - Escola Superior de Propaganda e Marketing, São Paulo, 2016.

POLIVANOV, Beatriz. Dinâmicas identitárias em sites de redes sociais: estudo com participantes de cenas de música eletrônica no Facebook. Rio de Janeiro: Multifoco, 2014.

RECUERO, Raquel. Redes sociais na internet. Porto Alegre: Sulina, 2009.

RIBEIRO, José Carlos. Um olhar sobre a sociabilidade no ciberespaço: aspectos sóciocomunicativos dos contatos interpessoais efetivados em uma plataforma interacional online. 2003. Tese (Doutorado em Comunicação e Cultura Contemporâneas) - Faculdade de Comunicação, Universidade Federal da Bahia, Salvador, 2003.

RIBEIRO, José Carlos; FALCÃO, Thiago; SILVA, Tarcízio. Gerenciamento de impressões pessoais através de aplicativos sociais: uma proposta de análise. In: CONGRESSO BRASILEIRO DE CIÊNCIAS DA COMUNICAÇÃO, 33., 2010, Caxias do Sul, 2010. Anais... Caxias do Sul: Intercom, 2010.

RIBEIRO, José; NEJM, Rodrigo; MIRANDA, Thais. Auto-revelação em ambientes digitais: reflexões sobre a privacidade de adolescentes em sites de redes sociais. In: SIMPÓSIO EM 
TECNOLOGIAS DIGITAIS E SOCIABILIDADE - SIMSOCIAL, 2012, Salvador, 2012. Anais... Salvador: Grupo de pesquisa em interação, tecnologias digitais e sociedade, 2012. p. [1-15].

RUSSEL. 'Marilene não se mete' viraliza nas redes sociais, assista ao vídeo. In: Blasting News, Chiasso, 26 set. 2016.

RUTTER, Jason.; SMITH, G. W. H. Ritual aspects of CMC sociability. In: ESPRIT I3 WORKSHOP ON ETHNOGRAPHIC STUDIES IN REAL AND VIRTUAL COMMUNITIES, 1999, Queen Margaret University College, Edinburgh. Proceedings... Edinburgh: Queen Margaret University College, 1999.

SCHAU, Hope; GILLY, Mary. We Are What We Post? self-presentation in personal web space. Journal of Consumer Research, Oxford, v. 30, n. 3, dez. 2003.

SHAVIRO, Steven. The Universe of Things. In: OBJECT-ORIENTED ONTOLOGY SYMPOSIUM, 2010, Atlanta. Proceedings... Atlanta: Georgia Tech, 2010.

SMITH, Greg. Erving Goffman. New York: Routledge, 2006.

UOL. Atriz Fernanda Paes Leme comete gafe no Twitter e vira piada. UOL, São Paulo 28 ago. 2014. UOL TV e famosos.

USKI, Suvi; LAMPINEN, Airi. Social norms and selfpresentation on social network sites: profile work in action. New Media \& Society, Thousand Oaks, v. 18, n. 3, p. 447-464, 2016.

WALTHER, Joseph. Selective self-presentation in computer-mediated communication: hypersonal dimensions of technology, language, and cognition. Computers in Human Behavior, Amsterdam, v. 23, n. 5, p. 2538-2557, Sept. 2007.

ZHAO, Shanyang; GRASMUCK, Sherri; MARTIN, Jason. Identity construction on Facebook: digital empowerment in anchored relationships. Computers in Human Behavior, Amsterdam, v. 24, n. 5, p. 1816-1836, 2008.

\title{
Performatic ruptures in social network sites:
}

a gaze at fissures in the process of selfpresentation based on and beyond Goffman

\begin{abstract}
A handful of studies has been dedicated to investigate the processes of self-presentation in social network sites. A large number of them is based on Goffman's dramaturgical perspective, focusing on how social actors build their "front" in these environments in order, in most of the cases, to keep the "expressive coherence" between their on and offline selves. However, we suggest in this paper we should look at the
\end{abstract}


moments of performatic ruptures, that is, when the actors' intentions are not fulfilled, causing unexpected effects. We argue - combined with an exploratory analysis of two illustrative cases - that, on one side, little attention has been paid to such ruptures and, on the other side, that to Goffman's perspective more contemporary theoretical background should be added in order to allow us to: a) understand the specificities of digital environments, and b) deal with several actants, humans and nonhumans, which are involved in these dynamics as fundamental mediators.

\section{Keywords}

Performatic ruptures. Social network sites. Goffman.

Recebido em 20/01/2018

Aceito em 18/05/2018 